\title{
Differentiated Thyroid Carcinoma That Express Sodium-Iodide Symporter Have a Lower Risk of Recurrence for Children and Adolescents
}

\author{
ANEETA PATEL, SISSY JHIANG, SHALINI DOGRA, RICHARD TERRELL, \\ PATRICIA A. POWERS, CYDNEY FENTON, CATHERINE A. DINAUER, \\ R. MICHAEL TUTTLE, AND GARY L. FRANCIS
}

\begin{abstract}
Department of Pediatrics, Uniformed Services University of the Health Sciences, Bethesda, Maryland, U.S.A. [A.P., S.D., R.T., P.A.P., C.F., C.A.D., G.L.F.]; Department of Endocrinology, Ohio State University, Columbus, Ohio, U.S.A. [S.J.]; Departments of Pediatrics [P.A.P., C.F., G.L.F.] and Clinical Investigation [C.A.D.], Walter Reed Army Medical Center, Washington, D.C., U.S.A.; and Department of Endocrinology, Memorial Sloan Kettering Cancer Center, New York, New York, U.S.A. [R.M.T.]
\end{abstract}

\begin{abstract}
The sodium-iodide symporter (NIS) is expressed by papillary (PTC) and follicular (FTC) thyroid carcinoma, and is essential for iodine uptake. We hypothesized that PTC and FTC with detectable NIS immunostaining would be more amenable to radioactive iodine $\left({ }^{131} \mathrm{I}\right)$ treatment and follow a more benevolent course. To test this, we determined NIS expression by immunohistochemistry in 23 PTC, 9 FTC, and 12 benign thyroid lesions from children and adolescents. NIS expression was determined by two blinded examiners and graded as absent $=0$, minimal $=$ 1 , moderate $=2$, intense $=3$, and very intense $=4$. NIS was detected in 35\% (eight of 23) of PTC, 44\% (four of 9) of FTC, $25 \%$ (two of eight) of benign tumors, and $100 \%$ (four of four) of autoimmune lesions. The intensity of NIS expression was similar in PTC $(0.61 \pm 0.24)$, FTC $(0.56 \pm 0.24)$, and benign tumors $(0.50 \pm 0.33)$ but was more intense in autoimmune lesions $(3.0$ $\pm 0.7, p<0.005)$. Distant metastases were found only among PTC with undetectable NIS (two of 15, 13\%), and recurrence developed exclusively from PTC and FTC with undetectable NIS (four of 20, 20\% versus zero of $12, p=0.043$ ). The dose of iodine 131 required to achieve remission in the five patients with
\end{abstract}

\section{ABSTRACT}

PTC who had undetectable NIS $(213.3 \pm 53 \mathrm{mCi})$ was greater than that required by patients with similar age and extent of disease for whom NIS expression is unknown $(109 \pm 22 \mathrm{mCi}, p$ $=0.06)$. We conclude that NIS expression is associated with a lower risk of recurrence for PTC and FTC of children and adolescents. (Pediatr Res 52: 737-744, 2002)

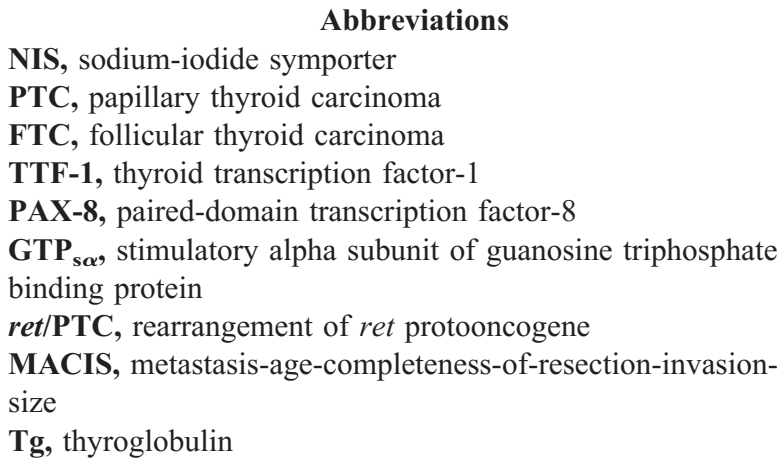

The NIS is a membrane-bound glycoprotein cotransporter expressed by thyroid, salivary, gastric, mammary, and extraocular tissues (1-4). NIS is essential for the uptake of iodide and thyroid hormone synthesis and is directly related to the level of thyroid

Received December 31, 2001; accepted April 3, 2002.

Address correspondence to: Gary L. Francis, M.D., Ph.D., Department of Pediatrics, Uniformed Services University of the Health Sciences, 4301 Jones Bridge Road, Bethesda, MD 20814, U.S.A.; e-mail: gfrancis@usuhs.mil

Supported by the Department of Clinical Investigation, Walter Reed Army Medical Center, Washington, DC, U.S.A., under WU \# 00-6501.

The opinions or assertions contained herein are the private views of the authors and are not to be construed as official or as reflecting the opinions of the Uniformed Services University of the Health Sciences, the Department of the Army, or the Department of Defense.

DOI: 10.1203/01.PDR.0000031920.28469.B8 differentiation (5-9). NIS expression is controlled by TSH and dependent on TTF-1 as well as PAX-8 (5, 10-15). Because of the central role of NIS in determining radioactive iodine uptake, it has been postulated that thyroid carcinoma that fail to express NIS would be resistant to radioactive iodine ablation (16).

In the normal thyroid, NIS expression is unequally distributed around individual thyroid follicles, and is most intense at the basolateral cell border (3, 14, 17-19). Such unequal NIS expression is also found at the macroscopic level, at which radioactive iodine scans reveal patchy uptake in thyroid tumors as well as in autoimmune thyroid disease (20). NIS is most highly expressed by Graves' tissue, in which a diffuse pattern of expression is characteristic $(4,21)$. 
A limited number of previous studies have used immunohistochemistry to examine NIS expression by thyroid carcinoma $(4,9,21-25)$. A previous study by Jhiang et al. (21) failed to detect NIS in any of the four adult thyroid carcinomas examined. A second study by Saito et al. (24) found NIS expressed by seven of 17 PTCs. The patients ranged in age from 17 to $68 \mathrm{y}$, and 11 of 17 had metastases to the cervical lymph nodes, but none had distant metastasis. A study by Castro et al. (23) found intermediate staining for NIS in two adult FTCs and one adult PTC. Caillou et al. (4) examined four thyroid carcinomas from patients aged 21-77 y. They were also able to show that all three of the PTCs with positive NIS staining incorporated radioactive iodine. A recent abstract by Wapnir et al. (25) detected NIS in $71 \%$ of PTCs, $33 \%$ of FTCs, and $66 \%$ of benign thyroid tumors. Unfortunately, there were insufficient clinical details in any of these studies to determine whether NIS expression had an impact on clinical outcome. Lazar et al. (26) used quantitative reverse transcriptase-PCR to examine NIS mRNA levels in 43 thyroid carcinomas from patients aged $46.6 \pm 13 \mathrm{y}$. NIS expression was lower in more advanced tumor stages. Using reverse transcriptase-PCR, Ringel et al. (10) found reduced NIS mRNA levels in $90 \%$ of adult thyroid carcinomas. All these studies suggest NIS expression is common in differentiated thyroid carcinomas from adults, but the importance of NIS expression in defining clinical outcome remains unknown.

Most importantly, no previous study included any children or adolescents with thyroid cancer. This is important because thyroid cancers in children and adolescents are welldifferentiated and therefore likely to express NIS. In addition, there are important clinical and molecular differences between thyroid cancers from children and adolescents compared with adults. First, thyroid cancers have a lower mortality rate but a higher recurrence rate in children and adolescents compared with adults (27-30). Although late recurrence can be seen, the vast majority of tumors that ever recur $(90 \%)$ do so within the first 7 y after treatment (29). Second, disease-free survival is lower in adult FTC compared with PTC, but similar in PTC and FTC from children and adolescents (29). Finally, the pattern of oncogene expression also appears to differ. Thyroid cancers from children are less likely to harbor activating mutations in $\mathrm{GTP}_{\mathrm{s} \alpha}$, but more likely to have rearrangements in $\mathrm{ret} / \mathrm{PTC}(31,32)$. Because of these differences, it is important to understand the impact of NIS expression on the outcome of childhood thyroid cancers.

The current study was designed to determine NIS expression in a group of benign and malignant thyroid lesions from children and adolescents and to correlate NIS expression with the clinical outcomes of thyroid cancer. Our results are consistent with the hypothesis that NIS expression is a favorable prognostic indicator for thyroid carcinoma in children and adolescents.

\section{METHODS}

Approval. This study received prior approval from the Human Use Committee of the Department of Clinical Investigation, Walter Reed Army Medical Center, Washington, DC, U.S.A.
Patients. The Automated Centralized Tumor Registry of the Department of Defense (ACTUR) was searched to identify all patients with differentiated thyroid carcinoma who were $21 \mathrm{y}$ of age or younger at the time of diagnosis. Original medical records were used to construct a computerized database that includes demographic features, tumor characteristics, surgical treatment, adjunctive therapy, and clinical outcome. The extent of disease at diagnosis was classified according to the system of DeGroot et al. $(33,34)$ and the MACIS score. According to DeGroot et al. (33), class 1 disease was confined to the thyroid gland; class 2 involved the regional lymph nodes; class 3 either extended beyond the capsule or was inadequately resected; and class 4 had distant metastasis. Because all patients were younger than $39 \mathrm{y}$ of age, MACIS scores were calculated as 3.1 $+($ size $\times 0.3)+1$ (if incomplete resection) +3 (if distant metastasis) (34). As in previous studies, recurrence was defined as the appearance of new disease (identified by radioactive iodine scan or biopsy) in any patient who had been free of disease (no disease palpable or identified by radioactive iodine scan) for a period of 4 mo after initial therapy (29). Serum $\mathrm{Tg}$ levels were determined in contemporary patients (normal: 3-40 ng/mL, University of Southern California Clinical Laboratories, Los Angeles, CA, U.S.A.). However, not all historical patients had $\mathrm{Tg}$ levels available during the course of treatment. For this reason, serum Tg levels are not included in this definition, but are presented where available. The patients with PTC and FTC had normal or low TSH levels, and were clinically euthyroid at the time the primary tumors used in this study were obtained. The clinical details for some of the patients in this group have been previously published (29).

Formalin-fixed, paraffin-embedded archival tumor blocks corresponding with 23 of the PTC, nine FTC, and 12 benign thyroid lesions (six benign follicular adenomas, three Graves' disease, two multinodular goiters, one Hashimoto's thyroiditis) were available for study. For analysis, the benign lesions were separated into two categories (benign tumors and autoimmune lesions) and compared with PTC and FTC.

Immunohistochemistry. Sections from original, formalinfixed, paraffin-embedded archival tissue blocks were sectioned and stained with hematoxylin and eosin to confirm the diagnosis $(35)$. The sections immediately adjacent $(5 \mu \mathrm{m})$ were used for immunohistochemistry. Sections were deparaffinized with xylene and rehydrated through a series of graded alcohol solutions followed by nuclease-free water. Endogenous peroxidase was inactivated $\left(3 \% \mathrm{H}_{2} \mathrm{O}_{2}, 30 \mathrm{~min}\right)$, and antigen was retrieved in citrate buffer ( $\mathrm{pH} 6.0,30 \mathrm{~min}, 100^{\circ} \mathrm{C}$, steamer). Tissue sections were sequentially incubated with primary rabbit polyclonal NIS antibody (1:500, room temperature, $1 \mathrm{~h}$ ) followed by detection using the Ventana Nexes automated immunostainer (Ventana Medical Systems, Tucson, AZ, U.S.A.) $(21,36,37)$. The secondary antibody and $\mathrm{ABC}$ reagent were obtained from the Elite Vector Kit (Vector Laboratories, Burlingame, CA, U.S.A.) and used according to the manufacturer's suggestions. The addition of substrate chromogen (diaminobenzidine) was performed manually (10 min, room temperature) followed by hematoxylin counterstain (30 s). Sections of adult Graves' disease were used as the positive control, and PBS was substituted for the primary and second- 
ary antibodies and used as the negative controls. The presence and intensity of NIS staining was determined by two blinded, independent examiners and graded as follows: $0=$ absent, $1=$ minimal, $2=$ moderate, $3=$ intense, and $4=$ very intense. The interobserver agreement was $>90 \%$, and the three discordant slides were graded by a third examiner. The two scores in agreement were then used as the final intensity grade. For some data analyses, tumors were stratified into two groups: those in which NIS was detected (grade 1-4) and those in which NIS was not detected (grade 0 ). Of importance, the interexaminer concordance for this distinction was 100\%.

Data analysis and statistical comparisons. The intensity of NIS expression for PTC, FTC, and benign lesions was then compared. The presence or absence of NIS immunostaining was also correlated with the demographic features, histologic variant, focality of the tumor, size of the tumor, extent of disease at diagnosis (class 1-4), MACIS score, and clinical outcome. Statistical analyses were performed using SPSS for Windows 95 (version 7.5, SPSS Inc., Chicago, IL, U.S.A.). The intensity of NIS expression was compared by ANOVA, correlations were performed using Pearson correlation, and nonparametric analyses were performed using either the $\chi^{2}$ or Fisher's exact test as indicated.

\section{RESULTS}

The specificity of NIS staining was confirmed using a sample of adult Graves' disease as a positive control, and PBS for the negative controls. In adult Graves' tissue, NIS was diffusely evident in a generalized distribution as previously reported (Fig. 1A) (21). When PBS was substituted for the primary or secondary antibody, NIS staining was completely abolished. In addition, there was no effect of the length of time each tumor block had been stored on the intensity of NIS staining $(r=0.22, p=0.30)$. Representative NIS staining for each intensity category is also shown in Figure $1(B$, grade $0=$ absent; $C$, grade $1=$ minimal; $D$, grade $2=$ moderate; $E$, grade $3=$ intense; and $F$, grade $4=$ very intense). Of note, NIS immunostaining of PTC and FTC was diffuse and cytoplasmic in location (Fig. 1, $B-D$ ) as reported for adults (21).

Demographic features and NIS immunostaining for individual cases of PTC and FTC are shown in Table 1. For patients with PTC, the average age was $16.1 \pm 4.3$ y (median, $16 \mathrm{y}$; range, $6-21 \mathrm{y}$ ), mean tumor size was $2.0 \pm 1.5 \mathrm{~cm}$ (range, $0.5-7.5 \mathrm{~cm})$, and the average follow-up was $48 \pm 42 \mathrm{mo}$ (range, 0-169 mo). Eight of the patients with PTC (35\%) were followed more than $5 \mathrm{y}$, and four (17\%) were followed more than 7 y. For patients with FTC, the average age was $18.3 \pm$ $2.0 \mathrm{y}$ (median, $19 \mathrm{y}$; range, 16-21 y), mean tumor size was 2.6 $\pm 1.4 \mathrm{~cm}$ (range, $0.2-4.0 \mathrm{~cm}$ ), and the average follow-up was $39 \pm 14 \mathrm{mo}$ (range, $18-60 \mathrm{mo}$ ). None of the patients with FTC was followed beyond $5 \mathrm{y}$. The demographic features of these patients with PTC and FTC are similar to the larger series previously published by our group (29).

Figure 2 compares NIS staining for PTC, FTC, benign thyroid tumors, and autoimmune lesions. NIS staining was of similar intensity for all benign and malignant thyroid tumors (PTC, $0.61 \pm 0.24$; FTC, $0.56 \pm 0.24$; benign tumors, $0.50 \pm$ $0.33)$. Overall, NIS was detected in two of eight benign tumors ( $25 \%$, both benign adenomas), $35 \%$ of PTCs, $44 \%$ of FTCs, and $100 \%$ of autoimmune lesions. Three of four $(75 \%)$ of the autoimmune lesions in this study were from children with Graves' disease. Because the most intense NIS expression has been found in adults with Graves' disease, we expected and found that mean staining intensity was significantly greater for childhood autoimmune thyroid lesions $(3.0 \pm 0.71)$ compared
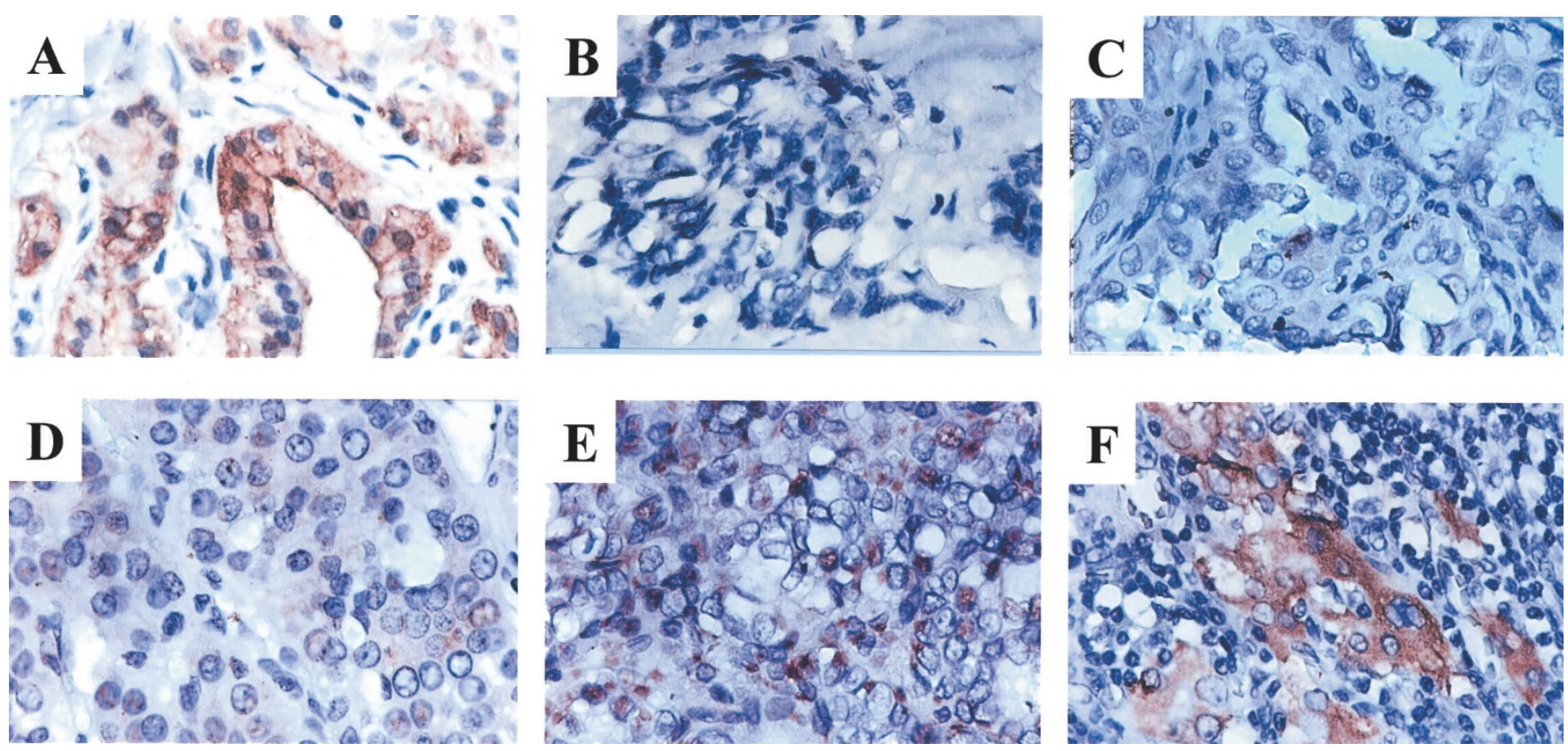

Figure 1. Representative immunostaining for NIS. $A$, intense, diffuse staining characteristic of Graves' disease. $B-F$, representative examples of NIS staining: grade $0(B$, absent), grade $1(C$, minimal), grade $2(D$, moderate), grade $3(E$, intense), and grade 4 ( $F$, very intense). All micrographs are shown at $\times 200$ magnification. 
Table 1. Individual patient demographics and NIS expression

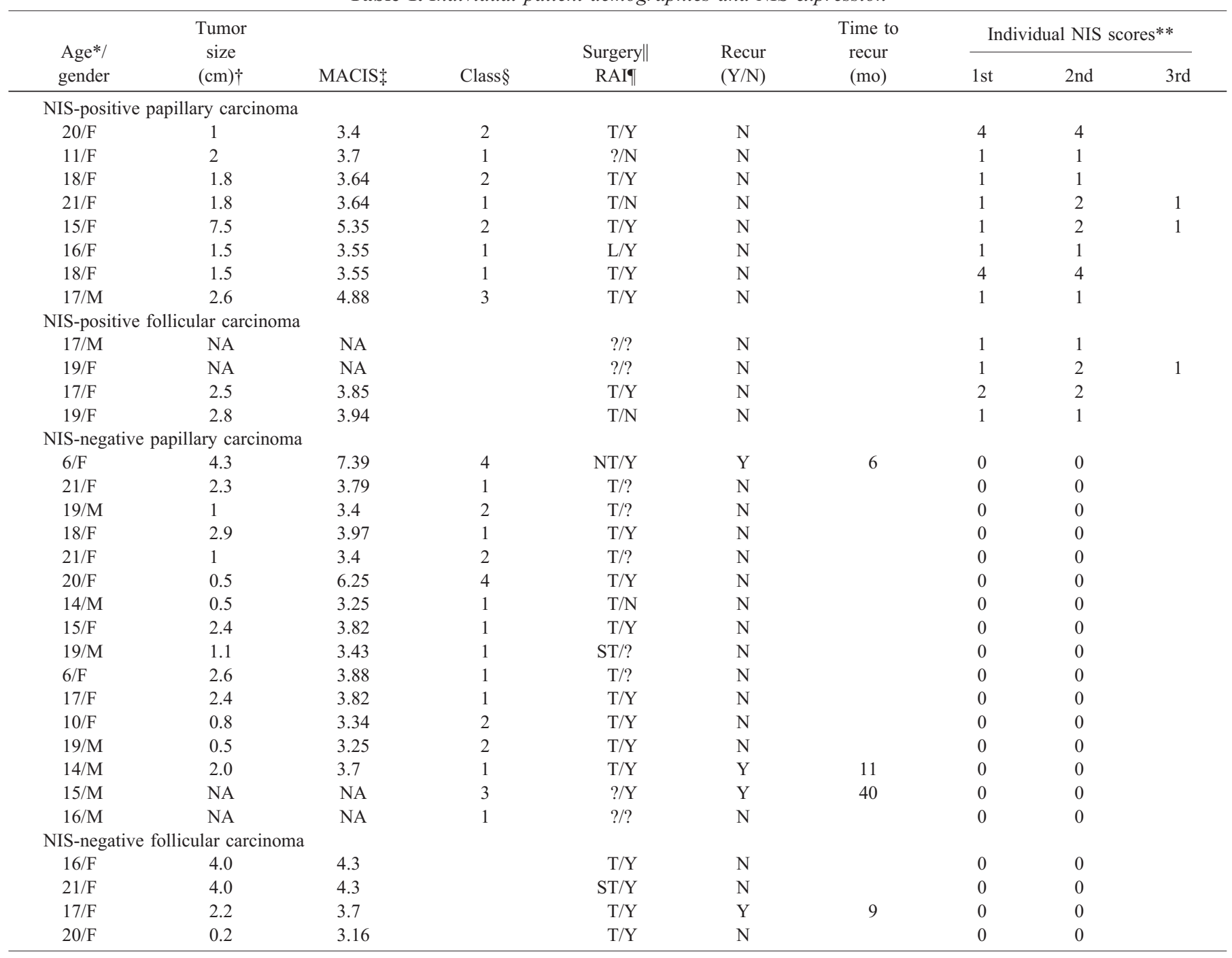

* Patient age in years.

$\dagger$ Tumor size along the longest tumor axis.

$\ddagger$ MACIS score $=3.1+($ size $\times 0.3)+1$ (if incomplete resection $)+3$ (if distant metastasis) 34 .

$\S$ Class according to the classification system of DeGroot et al.33 pertains only to PTC.

\| Surgery classified as total thyroidectomy (T), near-total (NT), subtotal (ST), lobectomy (L), or unknown (?) 29.

II RAI ablation given (Y) or not given $(\mathrm{N})$.

** Individual NIS scores are shown with the reading of the third scorer where required.

NA, not available; RAI, radioactive iodine.

with PTC $(0.61 \pm 0.24, p=0.001)$, FTC $(0.56 \pm 0.24, p=$ $0.001)$, and benign thyroid tumors $(0.50 \pm 0.33, p=0.004)$.

PTC and FTC were stratified into two groups: tumors with detectable NIS expression $(n=12)$, and tumors without detectable NIS expression $(n=20)$. As shown in Table 2, the extent of disease at diagnosis was similar when comparing the two groups, as were the average MACIS score and tumor size for both PTC and FTC. Of note, however, neither of the class 4 tumors in this study (PTC with distant metastasis) had detectable NIS. As shown in Table 2, the treatment received by patients with PTC or FTC who had detectable NIS was similar to that received by patients with PTC or FTC who had undetectable NIS.

Despite similar extent of disease at diagnosis, tumor size, and treatment, the overall recurrence risk was increased for tumors that had undetectable NIS expression. Recurrent dis- ease developed exclusively from tumors in which NIS was not detected (four of $20,20 \%, p=0.043$ ). The average time to recurrence was $16.5 \pm 7.9 \mathrm{mo}$ (range, $6-40 \mathrm{mo}$ ). This is shorter than the average time to recurrence for patients in our database with similar age and extent of disease at diagnosis, for whom NIS expression is unknown $(45 \pm 55 \mathrm{mo}, p=0.18$; Table 3). However, the difference did not achieve statistical significance. Two patients with PTC had very intense (grade 4) NIS immunostaining. Both were young women (18 and $20 \mathrm{y}$ of age) with unifocal, class 1 and class 2 disease. The PTC were small $(1.0$ and $1.5 \mathrm{~cm}$ ), and MACIS scores were low (3.4 and 3.55). Neither patient had a recurrence, and at last follow-up, both were alive without disease.

Detailed records of radioactive iodine treatments were available for five of the patients with PTC who had undetectable 


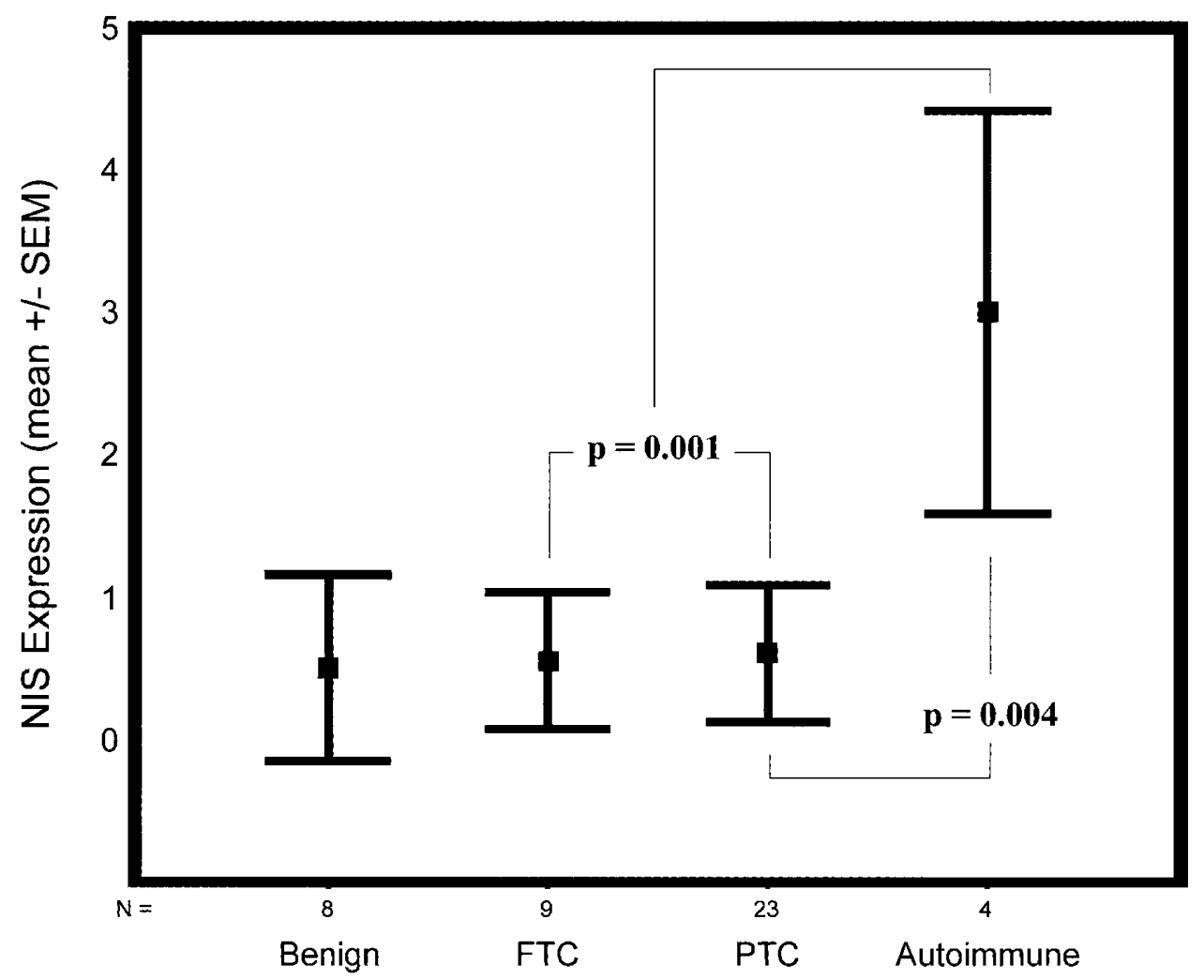

Figure 2. NIS expression among PTC, FTC, benign tumors, and autoimmune lesions. NIS expression was of similar intensity for benign and malignant tumors, but significantly more intense in autoimmune lesions.

NIS expression. Three of these patients had class 1 disease, one had class 2 disease, and one had class 4 disease (Table 3 ). Although four of five $(80 \%)$ were eventually free of disease, the dose of radioactive iodine required to achieve remission $(213.3 \pm 53 \mathrm{mCi})$ was higher than the average received by patients in our database with similar age and extent of disease for whom NIS expression is unknown $(109 \pm 22 \mathrm{mCi}, p=$ $0.06)$. Table 3 compares the radioactive iodine treatments received by these five patients stratified according to disease class. Patients with class 1 disease (confined to the thyroid) required significantly more radioactive iodine to achieve remission when NIS staining was absent $(224 \pm 56$ versus $66 \pm$ $16, p=0.02$ ). There were too few patients with more extensive disease to allow independent statistical comparison between the class 2 and class 4 patients.

\section{DISCUSSION}

Expression of NIS is a marker of differentiated thyroid function, and at least some level of NIS expression is essential for successful therapy of thyroid carcinoma using radioactive iodine ablation (1-16). The utility of NIS immunostaining has been previously studied but only on a limited number of adult thyroid carcinomas. In these adult samples, NIS was detected by immunohistochemistry in several, but not all, cases $(4,9$, 21-23). Unfortunately, none of these studies provided sufficient clinical details to determine whether NIS expression could be correlated with the response to therapy or the risk of recurrence. Furthermore, none of these studies included any significant numbers of children or adolescents. This latter omission is important, because several findings indicate that thyroid carcinoma of children and adolescents follow a more benign clinical course and may have a different pattern of growth factor and oncogene activation (27-32). For these reasons, the current study was designed to examine NIS expression among benign and malignant thyroid tumors and to correlate NIS expression with the outcome of thyroid carcinoma in children and adolescents.

The data show that NIS is detected in similar proportions of benign (25\%) and malignant (PTC, 35\%; and FTC, 44\%) thyroid tumors from children and adolescents $(p=0.41)$. This provides a potential explanation for the common observation that thyroid scintigraphy is generally unable to distinguish benign from malignant thyroid lesions (38). Our findings are consistent with previous studies of adult PTC, in which NIS was detected using immunohistochemistry in zero of four, seven of 17, three of three, and three of four adult PTCs $(4,9$, 21, 22). Furthermore, NIS immunostaining of PTC and FTC was diffuse and cytoplasmic in location, as has been previously reported $(4,9,21,22)$. In our study, the patients with PTC and FTC had normal or low TSH levels during surgery. It is possible that some of the variability in published findings could relate to variability in serum TSH levels. During thyroid hormone withdrawal for the treatment of thyroid carcinoma with radioactive iodine, the resultant TSH elevation could increase NIS expression above the detection threshold in a larger proportion of tumors $(5,10-15)$.

NIS expression had a significant impact on the clinical course of individual patients in our study population. First, 
Table 2. Clinical features and NIS expression for PTC and FTC

\begin{tabular}{|c|c|c|c|}
\hline & NIS positive & NIS negative & $p$ value \\
\hline Total & $n=12(37.5 \%)$ & $n=20(62.5 \%)$ & \\
\hline PTC/FTC & $8 / 4$ & $16 / 4$ & NS \\
\hline Gender $(\mathrm{M} / \mathrm{F})$ & $2 / 10$ & $7 / 13$ & NS \\
\hline Class 1 (PTC only) & 4/8 PTC $(50 \%)$ & 9/16 PTC (56\%) & NS \\
\hline Class 2 (PTC only) & $3 / 8$ PTC $(37.5 \%)$ & $4 / 16$ PTC $(25 \%)$ & NS \\
\hline Class 3 (PTC only) & 1/8 PTC $(12.5 \%)$ & $1 / 16$ PTC $(6.25 \%)$ & NS \\
\hline Tumor size $(\mathrm{cm})$ & $2.50 \pm 1.84$ & $1.92 \pm 1.30$ & NS \\
\hline Unifocal disease $(\%) \ddagger$ & $6(60 \%)$ & $11(61 \%)$ & NS \\
\hline Multifocal disease $(\%) \ddagger$ & $4(40 \%)$ & $7(39 \%)$ & NS \\
\hline \multicolumn{4}{|l|}{ Thyroid surgery } \\
\hline Total thyroidectomy & $8(88 \%)$ & $15(83 \%)$ & NS \\
\hline Near total thyroidectomy & 0 & $1(5.5 \%)$ & NS \\
\hline Only suspicious nodes removed & $3(50 \%)$ & $12(67 \%)$ & NS \\
\hline Modified radical neck dissection & $2(33 \%)$ & $4(22 \%)$ & NS \\
\hline Radical neck dissection & $1(17 \%)$ & $2(11 \%)$ & NS \\
\hline Unknown & 6 & 2 & \\
\hline RAI ablation & $7(58 \%)$ & $13(65 \%)$ & NS \\
\hline Follow-up (mo) & $33 \pm 31$ & $53 \pm 40$ & NS \\
\hline \multicolumn{4}{|l|}{ Outcome } \\
\hline Remission & $6(50 \%)$ & $11(55 \%)$ & NS \\
\hline Persistent disease & $4(33 \%)$ & $7(35 \%)$ & NS \\
\hline Recurrence & 0 & $4(20 \%)$ & 0.043 \\
\hline
\end{tabular}

* Class according to the classification system of DeGroot et al.33 pertains only to PTC.

$\dagger$ MACIS score $=3.1+($ size $\times 0.3)+1$ (if incomplete resection $)+3$ (if distant metastasis $) 34$.

$\$$ Focality indicates unifocal lesions or multifocal lesions based on microscopic examination.

RAI, radioactive iodine.

none of the PTC with distant metastases (lung or bone) at diagnosis had detectable NIS expression. Because NIS expression is a powerful indicator of thyroid differentiation, our data suggest the possibility of a subtle decrease in the level of differentiation among PTC that have acquired a metastatic phenotype (5-9). Second, tumors that failed to stain for NIS were more likely to recur $(p=0.043)$, despite the fact that all patients had similar extent of disease at diagnosis, similar tumor size, and similar treatment. Follow-up was slightly longer for patients who had tumors with undetectable NIS (53 \pm 40 mo versus $33 \pm 31 \mathrm{mo}$ ), but the difference was not statistically significant and all recurrent disease developed by 40 mo after diagnosis. Although late recurrence can be seen in childhood thyroid cancers, $90 \%$ of all recurrence develops in the first 84 mo after treatment (29). Although it is possible that some of these patients may go on to develop recurrent disease, the data support the hypothesis that thyroid tumors with detectable NIS expression have a reduced probability of recurrence.

Detailed radioactive iodine treatment records were available for five of the patients with PTC who failed to express NIS. Although four of five $(80 \%)$ were eventually free of disease, the dose of radioactive iodine required to achieve remission $(213.3 \pm 53 \mathrm{mCi})$ was higher than the average received by patients in our larger database with similar age and extent of disease for whom NIS expression is unknown $(109 \pm 22 \mathrm{mCi}$, $p=0.06)$. This difference was even more significant when comparing patients with class 1 disease (disease confined to the thyroid gland, $224 \pm 56 \mathrm{mCi}$ versus $66 \pm 16 \mathrm{mCi}, p=0.02$ ). Although NIS was not detected in this subset of tumors, they did respond to radioactive iodine ablation. All the tissues in this study were removed while the patients were clinically euthyroid, but NIS expression is exquisitely sensitive to TSH stimulation $(5,10-15)$. It is probable that during thyroid hormone withdrawal and the resultant TSH elevation used to prepare patients for radioactive iodine ablation, NIS expression would have been sufficiently increased to allow radioactive iodine uptake and successful treatment, albeit with increased doses.

The optimal treatment for PTC and FTC in children and adolescents is debated; however, both histologic variants have similar disease-free survival and have been similarly treated in children and adolescents $(29,30,39)$. For that reason, our cases of PTC and FTC were analyzed together. PTC and FTC are commonly treated using annual doses of radioactive iodine until the patient is free from disease $(30,39)$. The patients in our study were not treated with a prospective protocol, but they all received annual radioactive iodine treatments until they were free from disease. Our data support the theory that carcinoma with detectable NIS expression are more amenable to treatment with radioactive iodine than are carcinoma with undetectable NIS. However, our data are limited by the small 
Table 3. Radioactive iodine treatment of patients with PTC

\begin{tabular}{|c|c|c|c|}
\hline & NIS negative & NIS unknown & $p$ value \\
\hline Total & $n=5$ & $n=26$ & \\
\hline Gender $(\mathrm{M} / \mathrm{F})$ & $2 / 3$ & $8 / 18$ & NS \\
\hline \multicolumn{4}{|l|}{ Extent of disease at diagnosis (class)* } \\
\hline Class 2 (PTC only) & 1 & 9 & NS \\
\hline Class 3 (PTC only) & 0 & 2 & NS \\
\hline Class 4 (PTC only) & 1 & 2 & NS \\
\hline Unifocal disease $(\%)$ & $3(60 \%)$ & $13(50 \%)$ & NS \\
\hline Multifocal disease $(\%)+$ & $2(40 \%)$ & $13(50 \%)$ & NS \\
\hline \multicolumn{4}{|l|}{ Thyroid surgery } \\
\hline Total thyroidectomy & $4(80 \%)$ & $18(70 \%)$ & NS \\
\hline Near total thyroidectomy & $1(20 \%)$ & 0 & NS \\
\hline Subtotal thyroidectomy & 0 & $7(27 \%)$ & NS \\
\hline Modified radical neck dissection & 0 & $3(11 \%)$ & NS \\
\hline Radical neck dissection & 0 & $1(4 \%)$ & NS \\
\hline None & $1(20 \%)$ & $13(50 \%)$ & NS \\
\hline Unknown & $1(20 \%)$ & $2(8 \%)$ & NS \\
\hline $\begin{array}{l}\text { Cumulative dose to achieve remission } \\
(\mathrm{mCi}, \text { mean } \pm \mathrm{SEM}) \S\end{array}$ & $213 \pm 53$ & $109 \pm 22$ & 0.06 \\
\hline \multicolumn{4}{|l|}{ Stratified according to disease class } \\
\hline Class 1 & $224 \pm 56 \quad(n=3)$ & $66 \pm 16(n=13)$ & 0.02 \\
\hline Class 2 & $62.4(n=1)$ & $113 \pm 24 \quad(n=9)$ & \\
\hline Class 3 & none were class 3 & $125 \pm 25 \quad(n=2)$ & \\
\hline Class 4 & $333.4(n=1)$ & $350 \pm 200(n=2)$ & \\
\hline Follow-up (mo) & $\begin{array}{c}68.4 \pm 61.7 \\
(0-169)\end{array}$ & $\begin{array}{l}99 \pm 85 \\
(16-332)\end{array}$ & NS \\
\hline
\end{tabular}

* Class according to the classification system of DeGroot et al.33 pertains only to PTC.

$\dagger$ MACIS score $=3.1+($ size $\times 0.3)+1$ (if incomplete resection $)+3$ (if distant metastasis $) 34$.

$\$$ Focality indicates unifocal lesions or multifocal lesions based on microscopic examination.

$\S$ Cumulative dose of ${ }^{131} \mathrm{I}(\mathrm{mCi})$ required to achieve initial remission.

number of subjects, and by the retrospective nature of patient treatment and follow-up.

Serum Tg levels were available only on the contemporary patients. For this reason, we defined recurrence as the appearance of new disease identified by radioactive iodine scan or biopsy (29). It is possible that some of the historical patients who were believed to be free of disease might have had detectable serum $\mathrm{Tg}$ and could have been inappropriately categorized. Nevertheless, treatment of such scan-negative, Tg-positive patients is highly controversial (40). In addition, all contemporary patients who were designated free of disease had serum $\mathrm{Tg}$ values less than $2 \mathrm{ng} / \mathrm{mL}$. Further study of NIS expression is clearly warranted. However, our data are consistent with the hypothesis that failure to detect NIS by immunostaining in tumors from euthyroid patients is associated with a requirement for greater radioactive iodine doses to achieve remission and an increased recurrence risk.

\section{CONCLUSIONS}

In conclusion, our data show that NIS expression is a favorable prognostic indicator for differentiated thyroid carcinoma of children and adolescents. The risk for recurrence is significantly increased for carcinoma from euthyroid patients in whom NIS cannot be detected by immunostaining, and the doses of radioactive iodine required to achieve remission are larger. Additional study is required to validate these findings on a larger and more diverse patient population, but the data suggest the possibility that determination of NIS expression by immunohistochemistry could be used to stratify treatment and prognosticate for individual patients.

\section{REFERENCES}

1. Mitchell AM, Manley SW, Morris JC, Powell KA, Bergert ER, Mortimer RH 2001 Sodium iodide symporter (nis) gene expression in human placenta. Placenta 22:256258 
2. Nakamoto Y, Saga T, Misaki T, Kobayashi H, Sato N, Ishimori T, Kosugi S, Sakahara H, Konishi J 2000 Establishment and characterization of a breast cancer cell line expressing $\mathrm{Na}+$ /I- symporters for radioiodide concentrator gene therapy. J Nucl Med 41:1898-1904

3. Ajjan RA, Kamaruddin NA, Crisp M, Watson PF, Ludgate M, Weetman AP 1998 Regulation and tissue distribution of the human sodium iodide symporter gene. Clin Endocrinol (Oxf) 49:517-523

4. Caillou B, Troalen F, Baudin E, Talbot M, Filetti S, Schlumberger M, Bidart JM 1998 $\mathrm{Na}+$ /I- symporter distribution in human thyroid tissues: an immunohistochemical study. J Clin Endocrinol Metab 83:4102-4106

5. Pasca di Magliano M, Di Lauro R, Zannini M 2000 Pax8 has a key role in thyroid cell differentiation. Proc Natl Acad Sci USA 97:13144-13149

6. Schmutzler C, Kohrle J 2000 Retinoic acid redifferentiation therapy for thyroid cancer. Thyroid 10:393-406

7. Tanaka K, Otsuki T, Sonoo H, Yamamoto Y, Udagawa K, Kunisue H, Arime I, Yamamoto S, Kurebayashi J, Shimozuma K 2000 Semi-quantitative comparison of the differentiation markers and sodium iodide symporter messenger ribonucleic acids in papillary thyroid carcinomas using RT-PCR. Eur J Endocrinol 142:340-346

8. Ros P, Rossi DL, Acebron A, Santisteban P 1999 Thyroid-specific gene expression in the multi-step process of thyroid carcinogenesis. Biochimie 81:389-396

9. Arturi F, Russo D, Schlumberger M, du Villard JA, Caillou B, Vigneri P, Wicker R Chiefari E, Suarez HG, Filetti S 1998 Iodide symporter gene expression in human thyroid tumors. J Clin Endocrinol Metab 83:2493-2496

10. Ringel MD, Anderson J, Souza SL, Burch HB, Tambascia M, Shriver CD, Tuttle RM 2001 Expression of the sodium iodide symporter and thyroglobulin genes are reduced in papillary thyroid cancer. Mod Pathol 14:289-296

11. Riedel C, Levy O, Carrasco N 2001 Post-transcriptional regulation of the sodium/ iodide symporter (NIS) by thyrotropin. J Biol Chem 276:21458-21463

12. Eng PH, Cardona GR, Previti MC, Chin WW, Braverman LE 2001 Regulation of the sodium iodide symporter by iodide in FRTL-5 cells. Eur J Endocrinol 144:139-144

13. Arturi F, Russo D, Giuffrida D, Schlumberger M 2000 Sodium-iodide symporte (NIS) gene expression in lymph-node metastases of papillary thyroid carcinomas. Eur J Endocrinol 143:623-627

14. Pomerance M, Abdullah HB, Kamerji S, Correze C, Blondeau JP 2000 Thyroidstimulating hormone and cyclic AMP activate $\mathrm{p} 38$ mitogen- activated protein kinase cascade: involvement of protein kinase A, rac1, and reactive oxygen species. J Biol Chem 275:40539-40546

15. Kogai T, Schultz JJ, Johnson LS, Huang M, Brent GA 2000 Retinoic acid induces sodium/iodide symporter gene expression and radioiodide uptake in the MCF-7 breast cancer cell line. Proc Natl Acad Sci USA 97:8519-8524

16. Filetti S, Bidart JM, Arturi F, Caillou B, Russo D, Schlumberger M 1999 Sodium iodide symporter: a key transport system in thyroid cancer cell metabolism. Eur J Endocrinol 141:443-457

17. Spitzweg C, Morris JC 2000 The immune response to the iodide transporter Endocrinol Metab Clin North Am 29:389-398, viii

18. Spitzweg C, Joba W, Morris JC, Heufelder AE 1999 Regulation of sodium iodide symporter gene expression in FRTL-5 rat thyroid cells. Thyroid 9:821-830

19. Ajjan RA, Watson PF, Findlay C, Metcalfe RA, Crisp M, Ludgate M, Weetman AP 1998 The sodium iodide symporter gene and its regulation by cytokines found in autoimmunity. J Endocrinol 158:351-358

20. Thomas Jr CG, Croom 3rd RD 1987 Current management of the patient with autonomously functioning nodular goiter. Surg Clin North Am 67:315-328

21. Jhiang SM, Cho JY, Ryu KY, DeYoung BR, Smanik PA, McGaughy VR, Fischer AH, Mazzaferri EL 1998 An immunohistochemical study of Na+/I- symporter in human thyroid tissues and salivary gland tissues. Endocrinology 139:4416-4419
22. Lin JD, Chan EC, Chao TC, Chen KT, Hsueh C, Ho YS, Weng HF 2000 Expression of sodium iodide symporter in metastatic and follicular human thyroid tissues. Ann Oncol 11:625-629

23. Castro MR, Bergert ER, Beito TG, Roche PC, Ziesmer SC, Jhiang SM, Goellner JR, Morris JC 1999 Monoclonal antibodies against the human sodium iodide symporter: utility for immunocytochemistry of thyroid cancer. J Endocrinol 163:495-504

24. Saito T, Endo T, Kawaguchi A, Ikeda M, Katoh R, Kawaoi A, Muramatsu A, Onaya T 1998 Increased expression of the sodium/iodide symporter in papillary thyroid carcinomas. J Clin Invest 101:1296-1300

25. Wapnir IGR, Dohan O, Amenta P, Carrasco N 2001 NIS expression in thyroid cancer. Proc ASCO 20:336b

26. Lazar V, Bidart JM, Caillou B, Mahe C, Lacroix L, Filetti S, Schlumberger M 1999 Expression of the $\mathrm{Na}+/ \mathrm{I}-$ symporter gene in human thyroid tumors: a comparison study with other thyroid-specific genes. J Clin Endocrinol Metab 84:3228-3234

27. Feinmesser R, Lubin E, Segal K, Noyek A 1997 Carcinoma of the thyroid in children — a review. J Pediatr Endocrinol Metab 10:561-568

28. Zimmerman D 1997 Thyroid neoplasia in children [see comments]. Curr Opin Pediatr 9:413-418

29. Welch-Dinauer CA, Tuttle RM, Robie DK, McClellan DR, Svec RL, Adair C, Francis GL 1998 Clinical features associated with metastasis and recurrence of differentiated thyroid cancer in children, adolescents and young adults. Clin Endocrinol (Oxf) 49:619-6-28

30. McClellan DR, Francis GL 1996 Thyroid cancer in children, pregnant women, and patients with Graves' disease. Endocrinol Metab Clin North Am 25:27-48

31. Waldmann V, Rabes HM 1997 Absence of G(s)alpha gene mutations in childhood thyroid tumors after Chernobyl in contrast to sporadic adult thyroid neoplasia. Cancer Res 57:2358-2361

32. Fenton CL, Lukes Y, Nicholson D, Dinauer CA, Francis GL, Tuttle RM 2000 The ret/PTC mutations are common in sporadic papillary thyroid carcinoma of children and young adults. J Clin Endocrinol Metab 85:1170-1175

33. DeGroot LJ, Kaplan EL, McCormick M, Straus FH 1990 Natural history, treatment, and course of papillary thyroid carcinoma. J Clin Endocrinol Metab 71:414-424

34. Hay ID, Bergstralh EJ, Goellner JR, Ebersold JR, Grant CS 1993 Predicting outcome in papillary thyroid carcinoma: development of a reliable prognostic scoring system in a cohort of 1779 patients surgically treated at one institution during 1940 through 1989. Surgery $114: 1050-1058$

35. Hedinger C, Williams ED, Sobin LH 1989 The WHO histological classification of thyroid tumors: a commentary on the second edition. Cancer 63:908-911

36. Cho JY, Leveille R, Kao R, Rousset B, Parlow AF, Burak Jr WE, Mazzaferri EL, Jhiang SM 2000 Hormonal regulation of radioiodide uptake activity and $\mathrm{Na}+/ \mathrm{I}-$ symporter expression in mammary glands. J Clin Endocrinol Metab 85:2936-2943

37. Cho JY, Xing S, Liu X, Buckwalter TL, Hwa L, Sferra TJ, Chiu IM, Jhiang SM 2000 Expression and activity of human Na+/I- symporter in human glioma cells by adenovirus-mediated gene delivery. Gene Ther 7:740-749

38. Hung W 1992 Nodular thyroid disease and thyroid carcinoma. Pediatr Ann 21:50-57

39. Samaan NA, Schultz PN, Hickey RC, Goepfert H, Haynie TP, Johnston DA, Ordonez NG 1992 The results of various modalities of treatment of well differentiated thyroid carcinomas: a retrospective review of 1599 patients. J Clin Endocrinol Metab 75:714-720

40. Wartofsky L 2000 An approach to the management of patients with scan negative, thyroglobulin positive, differentiated thyroid carcinoma. In: Wartofsky L (ed) Thyroid Cancer: A Comprehensive Guide to Clinical Management. Humana Press, Totowa, NJ, pp 251-261 